Cite this: Soft Matter, 2014, 10, 578

\title{
Dry oil powders and oil foams stabilised by fluorinated clay platelet particles $\uparrow$
}

\begin{abstract}
Bernard P. Binks, ${ }^{* a}$ Tomoko Sekine ${ }^{\mathrm{b}}$ and Andrew T. Tyowua ${ }^{\mathrm{a}}$
A series of platelet sericite particles coated to different extents with a fluorinating agent has been characterised and their behaviour in mixtures with air and oil studied. The material which forms by vigorous shaking depends on both the surface tension of the oil and the surface energy of the particles which control their degree of wetting. Oil dispersions are formed in liquids of relatively low tension $\left(<22 \mathrm{mN} \mathrm{m}^{-1}\right)$, e.g. hexane and cyclomethicone, for all particles. Particle-stabilised air-in-oil foams form in liquids of higher tension, e.g. dodecane and phenyl silicone, where the advancing three-phase contact angle $\theta$, measured on a planar substrate composed of the particles into the liquid, lies between ca. $65^{\circ}$ and $120^{\circ}$. For oils of tension above $27 \mathrm{mN} \mathrm{m}^{-1}$ like squalane and liquid paraffin with particles for which $\theta>70^{\circ}$, we have discovered that dry oil powders in which oil drops stabilised by particles dispersed in air (oil-in-air) can be prepared by gentle mixing up to a critical oil : particle ratio (COPR) and do not leak oil. These powders, containing up to $80 \mathrm{wt} \%$ oil, release the encapsulated oil when sheared on a substrate. For many of the systems forming oil powders, stable liquid oil marbles can also be prepared. Above the COPR, catastrophic phase inversion occurs yielding an ultra-stable air-in-oil foam. We thus demonstrate the ability to disperse oil drops or air bubbles coated with particles within novel materials.
\end{abstract}

Received 30th October 2013

Accepted 28th November 2013

DOI: $10.1039 / \mathrm{c} 3 \mathrm{sm} 52748 \mathrm{~d}$

www.rsc.org/softmatter particles, respectively. ${ }^{12}$ Omniphilic particles have fairly large affinity for both water and oil and would stabilise a/w and a/o systems, whilst omniphobic particles having very little affinity for both water and oil tend to stabilise w/a and o/a systems. Oleophobic and omniphobic surfaces are created from hydrophilic precursors by surface chemical modification using suitable fluorocarbons of low surface energy. ${ }^{13-15}$ Other properties that also influence the type of final product formed in air-liquid systems include the solid-air interfacial energy or particle surface energy $\gamma_{\mathrm{sa}}$, liquid-air interfacial tension $\gamma_{\mathrm{la}}$ and the speed of mixing. ${ }^{16}$ In air-oil systems, it has been shown that with appropriate agitation, a combination of relatively low tension liquids and relatively high surface energy oleophilic particles yields a particle dispersion, but a combination of liquids of intermediate (high) tension and oleophobic particles of intermediate (low) surface energy gives oil foams (oil liquid marbles). ${ }^{7}$

Liquid marbles, first described by Aussillous and Quéré, ${ }^{10}$ are now widely studied ${ }^{17-20}$ and can be considered an element of dry liquid powdered materials, i.e. dry water (if the liquid is water) and dry oil powders (if the liquid is an oil). Dry water ${ }^{21}$ (dry oil) ${ }^{22}$ is a free-flowing powder containing numerous water (oil) droplets coated with small solid particles which are poorly wetted by them. The encapsulated liquid may be released by evaporation or on application of mechanical stress. The particles confer stability on the liquid droplets and allow them to move with minimum adhesion to a substrate. This principle is 
also used by nature, both in the self-cleaning mechanism of various plant leaves ${ }^{23}$ and in the excretion of honeydew globules from aphids. ${ }^{24}$ Even though both dry water and dry oil powders have significant potential applications in the cosmetic, pharmaceutical and other related industries, studies on them are few and far between, especially for dry oils. This is partly due to the relatively low surface tension of many oils and partly due to the relatively high surface energy of many colloidal particles. Reports on oil liquid marbles are also limited for the same reason. From thermodynamic considerations, ${ }^{25}$ this prevents particle adsorption and hence stabilisation of the related materials. ${ }^{7}$ Papers on dry water include those from Binks and co-workers,,$^{21,26,27}$ Forny et $a .^{28,29}$ and Carter et al. ${ }^{30,31}$ Catastrophic phase inversion of particle-stabilised air-water systems, from a/w foams to w/a powders (containing about $98 \mathrm{wt} \%$ of water with respect to the total mass) was demonstrated in ref. 21 , by either a progressive change in the silica particle hydrophobicity at constant air: water ratio or by changing the air: water ratio at fixed particle wettability. The change in particle wettability was linked to the first inversion, ${ }^{29}$ whilst change in the volume fraction of the phase(s) was crucial for inversion in the second case. Dry water has also been used to enhance the kinetics of heterogeneous catalytic hydrogenation ${ }^{\mathbf{3 0}}$ and to enhance gas uptake rates in gas hydrates. ${ }^{31}$ On dry oil powders, Murakami and Bismarck ${ }^{22}$ used agglomerated oligomeric tetrafluoroethylene (OTFE) particles to prepare dry oil powders (containing $10-15 \mathrm{wt} \%$ of oil relative to the total mass). The dry oil powders were prepared by spraying oils from a spray gun on particles placed on a Tefal frying pan. A different preparation of dry oil powders employed protein ${ }^{32}$ or particle-stabilised ${ }^{33}$ $\mathrm{o} / \mathrm{w}$ emulsions as precursors followed by slow or rapid drying. Following this protocol, an oil powder containing about $90 \mathrm{wt}$ $\%$ of oil relative to the total mass which showed no sign of oil leakage over several months was prepared. This process however requires high energy and the drying stage is time consuming. A similar procedure which does not require evaporation of the continuous phase has been used to prepare oil-in-water-in-air (o/w/a) materials termed either a powdered emulsion $^{34}$ or a dry water emulsion. ${ }^{35}$ To obtain powdered emulsions, ${ }^{34}$ particle-stabilised $\mathrm{o} / \mathrm{w}$ emulsions stable to coalescence were aerated with very hydrophobic solid particles using a blender at high shear. The hydrophobic particles coat the newly created water globules in air which encase the oil drops in water. Similarly, o/w emulsions stabilised by branched copolymer surfactant were diluted before aerating in the presence of hydrophobic silica nanoparticles to obtain the dry water emulsion. ${ }^{35}$ To the best of our knowledge, a systematic study on the preparation of dry oil powders is yet to be reported. In this study, using fluorinated solid particles of varying surface energy and polar oils and $n$-alkanes of varying surface tension and low shear, we show that dry oil powders containing up to $80 \mathrm{wt} \%$ of oil (relative to the total mass) can be prepared by simply hand shaking a mixture of solid particles and oil, and that the dry oil powder may invert to an ultrastable oil foam at high oil : particle ratios. The findings are discussed in relation to the three-phase contact angle.

\section{Experimental}

\section{Materials}

Perfluoroalkyl phosphate (PF) treated particles used in this study were prepared by Daito Kasei Kogyo Company Ltd., Japan. Such particles are common in cosmetics enabling the preparation of a long lasting make-up resilient to perspiration and sebum thus promoting a more natural and healthy appearance. The particles (PF-5, 8, 10 and 12) were obtained by coating raw hydrophilic sericite particles (PF-0) with varying amounts of $\mathrm{C}_{9}-$ $\mathrm{C}_{15}$ perfluoroalkyl phosphate diethanolamine salt, $\left[\mathrm{F}_{3} \mathrm{C}\left(\mathrm{CF}_{2}\right)_{n}\left(\mathrm{CH}_{2}\right)_{2} \mathrm{O}\right]_{m} \mathrm{POO}\left[\mathrm{ONH}_{2}\left(\mathrm{CH}_{2} \mathrm{CH}_{2} \mathrm{OH}\right)_{2}\right]_{2}$, (where $n=6-$ 18 and $2>m>1$ ), which resulted in varying degrees of oleophobicity, with the PF-12 particles being the most oleophobic. Prior to fluorination, sericite particles are mixed with sodium aluminate and sulphuric acid leading to the formation of small crystals of $\mathrm{Al}(\mathrm{OH})_{3}$ on their surfaces rendering them positively charged and enabling an easy and uniform reaction with the anionic phosphate reactant. Sericite is a white, monoclinic, powdered mica mineral composed mainly of $\mathrm{SiO}_{2}(\sim 54 \%)$, $\mathrm{Al}_{2} \mathrm{O}_{3}(\sim 31 \%)$ and $\mathrm{K}_{2} \mathrm{O}(\sim 7 \%)$. The particles are plate-like of average size around $5 \mu \mathrm{m}$. They have a three-layer unit cell consisting of a $\mathrm{SiO}_{2}$ tetrahedron, an $\mathrm{Al}_{2} \mathrm{O}_{3}$ octahedron and a $\mathrm{SiO}_{2}$ tetrahedron held together by potassium ionic bonds. ${ }^{36}$ During chemical modification of the particles, the intermediate perfluoroalkyl phosphoric acid bonds to the particle surface through the formation of metal salts and/or hydrogen bonding depending on the alkalinity of the particles and imparts oleophobic properties to the particle surfaces.

The oils, used as received from Shiseido Japan, were of different types and they include silicone, mineral, vegetable, ester and UV-absorbing oils. The name, chemical structure and density of these oils are given in Table 1 . For comparison, $n$ alkanes $\left(\mathrm{C}_{5}-\mathrm{C}_{16}\right)$ were also used. Such alkanes include pentane (Aldrich, ca. 98\%), hexane (Fisher Scientific, ca. 95\%), heptane (Sigma-Aldrich, ca. 99\%), octane (Sigma-Aldrich, >98\%), decane (Avocado, ca. 99\%), dodecane (Sigma, $\geq 99 \%$ ), tetradecane (Aldrich, $\mathrm{ca}$. $>99 \%$ ) and general purpose grade hexadecane from Fisher Scientific. Air used was that present in the laboratory $\left(\mathrm{N}_{2}\right.$ $\approx 78 \%, \mathrm{O}_{2} \approx 21 \%, \mathrm{Ar} \approx 0.9 \%, \mathrm{CO}_{2} \approx 0.04 \%$ ). Water was passed through an Elga Prima reverse osmosis unit and then a Milli-Q reagent water system. The treated water has a surface tension of $72.0 \mathrm{mN} \mathrm{m}^{-1}$, pH of 6.9 and resistivity of $18 \mathrm{M} \Omega \mathrm{cm}$ at $25{ }^{\circ} \mathrm{C}$. Five other liquids (in addition to hexadecane and water) from Sigma-Aldrich were used as probe liquids to estimate the surface energies of particles from contact angle data. They include $\alpha$-bromonaphthalene (97\%), diiodomethane (99\%), ethylene glycol (>99\%), formamide (>99\%) and glycerol (99\%).

\section{Methods}

(i) Characterisation of particles. Scanning electron microscopy (SEM) was used to characterise the particles in terms of morphology and elemental content. SEM images were obtained from the powdered particles whilst their elemental composition was gathered from compressed disks of the particles (see later). To obtain an evenly distributed layer of dry 
Table 1 Name, chemical structure and density (at $25^{\circ} \mathrm{C}$ ) of some of the oils used

Name

Cyclomethicone

$6 \mathrm{cS}$ Polydimethylsiloxane (PDMS) $(n=5-10)$

Polydiphenylsiloxane

Isocetane

Squalane

Liquid paraffin

Macadamia nuts oil

Jojoba oil

Tripropylene glycol trimethylacetate

Glyceryl tri(2-ethylhexanoate)

Pentaerythritol tetra(2-ethylhexanoate)
Chemical structure

Density/g $\mathrm{cm}^{-3}$

0.956

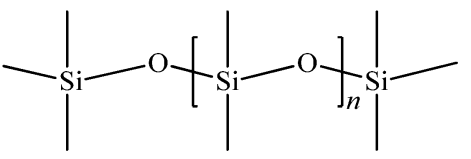

0.926

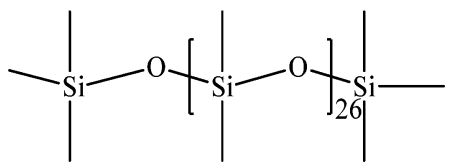

0.950<smiles>C[Si](C)(C)O[Si](C)(c1ccccc1)c1ccccc1</smiles>

0.990<smiles>CC(CC(C)(C)C)CC(C)(C)CC(C)(C)C</smiles>

0.792

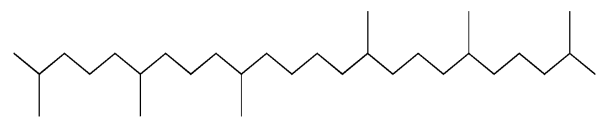

0.813

Mixture of long chain alkanes

0.855

Mixture of triglycerides of oleic, palmitoleic, linoleic and linolenic acids

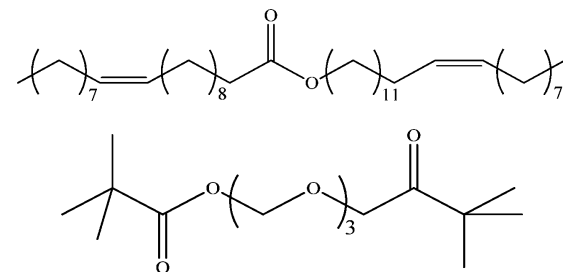

0.913<smiles>CCCCC(CC)C(=O)OCC(COC(=O)C(CCC)CCCC)OC(=O)C(CCC)CCCC</smiles><smiles>CCCCC(CC)C(=O)OCC12COC(=O)C(CCCC)CC(C)C(CCCC)C(=O)OCC(COC(=O)C(CC)CCCC)(C1)OC2</smiles><smiles>CCCCC(CC)C(=O)OCC(C)(C)C</smiles>

0.952

0.949

0.867

0.961 
Table 1 (Contd.)

Name

sericite particles for SEM, a sample mount (carbon sticky disk) containing a self-adhesive was pressed into a powder bed of the particles. Loosely held particles were removed with compressed air. The sample mount was then thermally coated with a thin layer ( $c a .15 \mathrm{~nm}$ ) of carbon using an Edwards high vacuum coating unit and examined with a Zeiss EVO 60 SEM at a beam current of $40 \mu \mathrm{A}$ and probe current of $101 \mathrm{pA}$. Using similar conditions, particle disks were stuck to the SEM sample mount and probed for elemental content. Their energy dispersive X-ray (EDX) elemental maps were also stored and processed (Fig. S1†). The SEM images (Fig. 1) show that PF-0 particles are made up of agglomerated, relatively smooth platelet particles (primary particle size $c a .2 \mu \mathrm{m}$ and several $\mathrm{nm}$ thick) compared to the treated ones which are discrete and textured. Crystals of $\mathrm{Al}(\mathrm{OH})_{3}$ of around $200 \mathrm{~nm}$ can be seen on the latter. Elemental analysis shows that the particles contain $\mathrm{C}, \mathrm{O}, \mathrm{F}, \mathrm{Na}, \mathrm{Mg}, \mathrm{Al}, \mathrm{Si}, \mathrm{P}, \mathrm{S}, \mathrm{Cl}$, $\mathrm{K}$, Ti and Fe (Table S1 $\dagger$ ), just like many other sericite particles. ${ }^{37}$ Fluorine is present in varying amounts depending on the degree of fluorination.

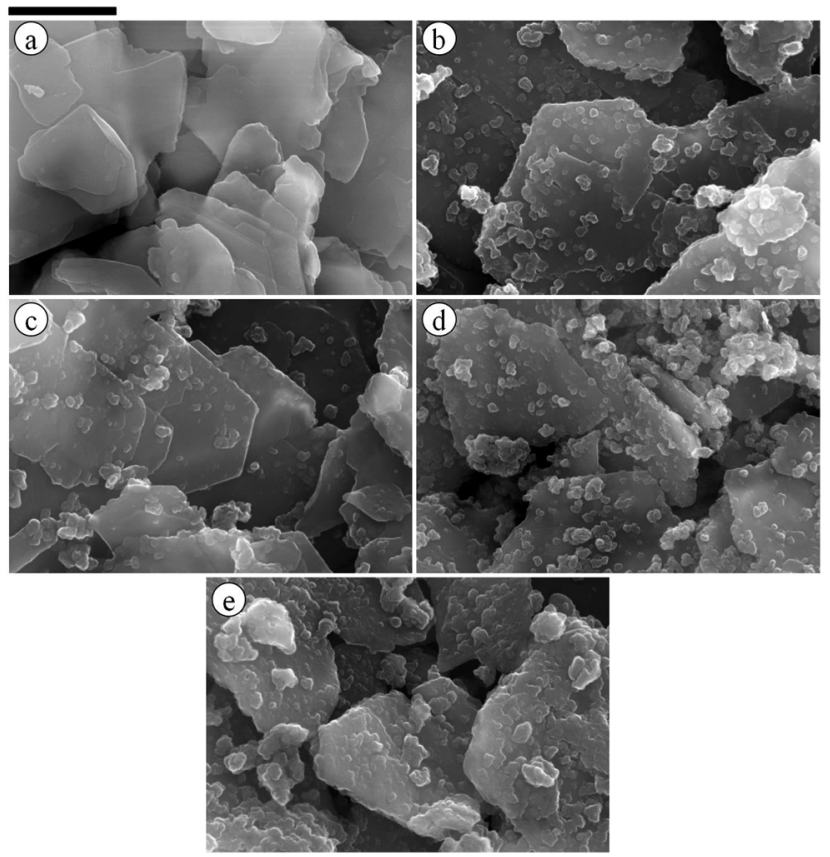

Fig. 1 SEM images of powdered sericite particles: PF-(a) 0, (b) 5, (c) 8 , (d) 10 and (c) 12. Scale bar $=2 \mu \mathrm{m}$. (ii) Surface energy of particles and contact angles. The surface energy, $\gamma_{\mathrm{sa}}$, of the various solid (s) particles was estimated from contact angle $(\theta)$ values of seven probe liquids in air (a). That of a PTFE substrate was also measured for comparison. Since it is difficult to measure the contact angle which small solid particles make with liquid surfaces especially if they are irregular and polydisperse, relatively smooth disks (diameter 13 $\mathrm{mm}$ and thickness $\sim 1 \mathrm{~mm}$ ) of the particles were used to gain an idea of $\theta$, using the sessile drop technique. The disks were obtained by compressing $c a .400 \mathrm{mg}$ of dry particles in a $13 \mathrm{~mm}$ diameter steel die with a hydraulic press (Research \& Industrial Instrument Co., UK) under a pressure of approximately $9.0 \times$ $10^{8} \mathrm{~N} \mathrm{~m}^{-2}$. For all the liquids, both the advancing $\left(0.1 \mathrm{~cm}^{3}\right.$ of liquid) and receding contact angle $\left(0.05 \mathrm{~cm}^{3}\right)$ were measured. Values of $\theta$ were measured with a Krüss DSA Mk 10 apparatus, by obtaining a profile of a liquid droplet on the particle disks. An average of 4 separate measurements is reported.

(iii) Characterisation of oils and other liquids. The density $\rho$ of the oils was determined with an Anton Paar DMA 35N digital densiometer at $25^{\circ} \mathrm{C}$, and 3 separate measurements were averaged. The cleaning of the instrument consisted of washing with copious amounts of ethanol and water. Determination of the liquid (l)-air (a) surface tension, $\gamma_{\mathrm{la}}$, at $25{ }^{\circ} \mathrm{C}$ was with a Krüss K12 digital tensiometer using the du Noüy ring method with appropriate correction. The results of 3 separate measurements were also averaged. The cleaning procedure involved rinsing the vessels in $0.5 \mathrm{M}$ alcoholic $\mathrm{KOH}$ solution and then with Milli-Q water. The ring was heated to glowing in a blue Bunsen flame prior to all measurements.

(iv) Particle immersion test with agitation. The required volume $\left(3 \mathrm{~cm}^{3}\right)$ of the desired oil was measured into a screw cap glass vessel (i.d. $1.8 \mathrm{~cm}, h .7 .2 \mathrm{~cm}$ ). The vessel was closed tightly after placing the required amount of particles $(50 \mathrm{mg})$ on the surface of the oil and observing if they entered the oil or not. After about $4 \mathrm{~h}$ these oil-particle mixtures were hand shaken vigorously for $30 \mathrm{~s}$ in a vertical motion. The formation of particle dispersions, oil foams or climbing films was noted. It was confirmed that foam or climbing film do not appear in these liquids in the absence of particles. 20 cS PDMS/PF-10 and isocetane/PF-10 are good examples of systems in which only foam was observed. As a result, the effect of dispersing the particles in the liquids before shaking was investigated on them. The PF-10 particles $\left(50 \mathrm{mg}\right.$ ) were dispersed in $3 \mathrm{~cm}^{3}$ of the liquids using a Branson ultrasonic sonifier for $2 \mathrm{~min}$ at $30 \%$ amplitude, followed by vigorous hand shaking ( $30 \mathrm{~s})$ and observed whether 
they still foam or not. Using ultrasound, it was necessary to cool the mixture in an ice bath. Photographs of the vessels containing the materials obtained and other photographs shown were taken with a $4.3 \mathrm{~V}$ Power Shot SX220 HS Canon digital camera.

(v) Preparation of oil marbles and dry oil powders. Oil marbles were prepared by releasing a droplet $(10 \mu \mathrm{L})$ of the desired oil from an Eppendorf micropipette onto a dry bed (100 $\mathrm{mg})$ of the particles placed on a Teflon substrate $(4 \mathrm{~cm} \times 4 \mathrm{~cm} \times$ $3 \mathrm{~mm}$, Radio Spares UK) positioned at $0.5 \mathrm{~cm}$ from the micropipette, and rolling it on the particle bed (to and fro) at an angle of approx. $45^{\circ}$. The Teflon substrate was washed with a warm solution of liquid soap in water, rinsed with clean water at the same temperature and then wiped with a clean white soft tissue prior to the experiment.

It was anticipated that dry oil powder formation would be possible with all the oil/particle combinations that gave oil liquid marbles. Nonetheless, knowing the amount of particles that must cover a known mass of oil to give it a dry oil powder appearance is fundamental. The critical oil : particle ratio, COPR, for the dry oil appearance defined as grams of oil per gram of particles, was determined by sequential addition of a small amount $(\leq 0.25 \mathrm{~g}$ ) of oil to $0.5 \mathrm{~g}$ of particles in a screw cap glass vessel, followed by gentle hand shaking ( $3 \mathrm{~min}$ ). Above the COPR the mixture foamed. Conscious of this, attempts were made to prepare dry oils using five approaches. The first is described above. With this method, dry oil powder formation was possible for the majority of the oils and the PF-treated particle combinations that gave oil marbles previously. It was confirmed using liquid paraffin and jojoba oil and PF-8 particles that the sequential addition of oil to the particles serves to increase the size of oil droplets in the dry oil powder. The second approach also involves sequential addition of oil $(\leq 0.25$ $\mathrm{g}$ ) but it is followed by vigorous hand shaking (3 $\mathrm{min})$. In the third approach, using liquid paraffin or jojoba oil and PF-8 particles as well as 2-ethylhexyl-4-methoxycinnamate and PF-12 particles, the kind of materials formed at $0.2 \mathrm{~g}$ of oil below and above the COPR in a non-sequential procedure that lasted for at least 10 min was investigated. The required amount of oil was added at once to the particles $(0.5 \mathrm{~g})$ and hand shaken gently for the said time. This approach yielded a dry oil powder below the COPR and oil foam above it for liquid paraffin and jojoba oil, but foam for 2-ethylhexyl-4-methoxycinnamate in both cases. In the fourth, the amount of oil corresponding to the COPR was added at once to $0.5 \mathrm{~g}$ of particles in the glass vessel followed by gentle hand shaking (5 min). Using squalane, liquid paraffin and glyceryl tri(2-ethylhexanoate), this approach in which a large oil droplet hardly breaks into smaller ones yields a foam instead of a dry oil powder. Lastly, for liquid paraffin, macadamia nuts oil, jojoba oil and 2-ethylhexyl-4-methoxycinnamate and PF-5, 8, 10 and 12, attempts were made at preparing dry oil powders using an IKA T25 ultra turrax homogeniser (i.e. high shear) at between 4000 and $13000 \mathrm{rpm}$ for 2 min below and above the COPR. A known mass of oil $(0.2 \mathrm{~g}$ below or above COPR) was weighed into a glass vessel, followed by addition of particles $(0.5 \mathrm{~g})$ and then sheared. In a parallel approach, the particles were placed in the glass vessel before oil addition and then sheared. Only oil foams were obtained with both approaches. Thus, dry oil powders were prepared mainly via the first method as it gives powders with relatively high oil content for the majority of the oil-particle combinations. Unless stated otherwise, properties of dry oil powders described hereafter are those at the COPR.

(vi) Characterisation of dry oil powders and oil foams. Apart from visual observation, the dispersion test was used to distinguish a dry oil powder from an oil foam. A known mass (ca. $400 \mathrm{mg}$ ) of the material for a known oil was placed on the surface of the oil $\left(c a .20 \mathrm{~cm}^{3}\right)$, stirred vigorously and observed whether it dispersed or not. Oil continuous materials (foams) dispersed, but air continuous materials (dry oil powders) did not. Furthermore, small samples of the various materials were placed on a dimple glass slide (Fisher scientific) and viewed with an Olympus BX-51 microscope fitted with a DP50 digital camera using Image-Pro Plus 5.1 software (Media Cybernetics). Cryo-SEM was also carried out in one case. Dry oil powder was sprinkled onto a perforated aluminium stub and plunged into liquid nitrogen slush $\left(-210^{\circ} \mathrm{C}\right)$. The frozen sample was transferred to a cryo system (Quorum Technologies PP3010T), sputter coated with platinum and transferred to the SEM cold stage and examined at $-140{ }^{\circ} \mathrm{C}$ at a beam voltage of $15 \mathrm{kV}$ and probe current of between 20 and 35 pA. An indication of whether the dry oil powders leak or not was obtained by placing them on a Sartorius Stedim filter paper (diameter $70 \mathrm{~mm}$ ) or a clean Pyrex watch glass (diameter $50 \mathrm{~mm}$ ) for $1 \mathrm{~min}$. The filter paper and watch glass were observed for degrees of oil staining after removal of the dry oil powders. To investigate the effect of shear on the dry oil powders, $8.5 \mathrm{mg}$ of powder was placed on the back of a hand (surface area $c a .13 \mathrm{~cm}^{2}$ ) and sheared at room temperature with an index finger. Dry oil powders $(0.5 \mathrm{~g})$ of squalane, liquid paraffin and jojoba oil stabilised by PF-8 particles were shaken vigorously $(10 \mathrm{~s})$ in a screw cap glass vessel to also verify the effect of shear on the powdered materials.

\section{Results and discussion}

Firstly, the surface energy of the various particles is determined from advancing contact angle data of probe liquids. This is followed by a description of the behaviour of the particles on the surface of the liquids. Thirdly, we describe the characteristics of the oil liquid marbles and dry oil powders and how the latter invert to ultra-stable oil foams at relatively high oil : particle ratios. Lastly, a correlation between the formation of oil dispersions, oil foams, and dry oil powders with contact angle data is made.

\section{Particle surface energies}

The surface energies of solid particles, $\gamma_{\text {sa }}$, and the surface tensions of liquids are commonly decomposed into their polar $\gamma^{\mathrm{P}}$ and dispersive $\gamma^{\mathrm{d}}$ components as: $:^{38,39}$

$$
\gamma=\gamma^{\mathrm{d}}+\gamma^{\mathrm{p}}
$$


The polar component is due to dipolar interactions whilst the dispersive component comes from van der Waals forces between the molecules of the material. ${ }^{40}$ The interfacial tension $\gamma_{\mathrm{AB}}$ between two phases A and B is then expressed in terms of the two components for each phase as given by eqn (2),

$$
\gamma_{\mathrm{AB}}=\gamma_{\mathrm{A}}+\gamma_{\mathrm{B}}-2\left(\sqrt{\gamma_{\mathrm{A}}^{\mathrm{d}} \gamma_{\mathrm{B}}^{\mathrm{d}}}+\sqrt{\gamma_{\mathrm{A}}^{\mathrm{p}} \gamma_{\mathrm{B}}^{\mathrm{p}}}\right)
$$

where $\gamma_{A}\left(\gamma_{B}\right)$ is the surface tension of phase A (B) and $\gamma_{A(B)}^{d}$ and $\gamma_{\mathrm{A}(\mathrm{B})}^{\mathrm{P}}$ represent the dispersive and polar components of the surface tension of the phases, respectively. The Young equation $^{41}$ developed for perfectly smooth and chemically homogeneous surfaces, relates the contact angle $\theta$ of a liquid droplet on a substrate to $\gamma_{\mathrm{la}}, \gamma_{\mathrm{sa}}$ and the solid-liquid interfacial tension $\gamma_{\mathrm{sl}}$

$$
\cos \theta=\frac{\gamma_{\mathrm{sa}}-\gamma_{\mathrm{sl}}}{\gamma_{\mathrm{la}}}
$$

It can be combined with eqn (4) to give eqn 5 (ref. 7 and 42)

$$
\begin{gathered}
\gamma_{\mathrm{sl}}=\gamma_{\mathrm{la}}+\gamma_{\mathrm{sa}}-2\left(\sqrt{\gamma_{\mathrm{sa}}^{\mathrm{d}} \gamma_{\mathrm{la}}^{\mathrm{d}}}+\sqrt{\gamma_{\mathrm{sa}}^{\mathrm{p}} \gamma_{\mathrm{la}}^{\mathrm{p}}}\right) \\
\frac{1}{2} \gamma_{\mathrm{la}}(1+\cos \theta)=\sqrt{\gamma_{\mathrm{sa}}^{\mathrm{d}} \gamma_{\mathrm{la}}^{\mathrm{d}}}+\sqrt{\gamma_{\mathrm{sa}}^{\mathrm{p}} \gamma_{\mathrm{la}}^{\mathrm{p}}}
\end{gathered}
$$

Eqn 5 contains two unknowns, $\gamma_{\mathrm{sa}}^{\mathrm{d}}$ and $\gamma_{\mathrm{sa}}^{\mathrm{p}}$, the components of the solid surface energy as the other terms exist in the literature for many liquids. Finding the unknowns requires $\theta$ from at least two liquids of different polarity so that simultaneous versions of eqn (5) can be solved. As shown previously, ${ }^{42}$ it is more useful to use several probe liquids (water, glycerol, formamide, ethylene glycol, diiodomethane, $\alpha$-bromonaphthalene and $n$-hexadecane) and to perform a least-squares calculation to determine the best combination of $\gamma_{\mathrm{sa}}^{\mathrm{d}}$ and $\gamma_{\mathrm{sa}}^{\mathrm{p}}$ that fits all the liquids simultaneously. The advancing $\theta$ of these liquids on relatively smooth disks composed of the sericite particles in air are given in Table 2. This approach is exemplified in Fig. 2 for the oleophilic and two fluorinated particles and in Fig. S2† for the rest of them. The 3-D surface energy charts are plots of the goodness of fit (=inverse of squares of variances) to $\theta$ set against a matrix of possible values of $\gamma_{\mathrm{sa}}^{\mathrm{d}}$ and $\gamma_{\mathrm{sa}}^{\mathrm{p}}$. The best fit to all $\theta$ is read from the coordinates of the peak and the values are given in Table 3. This gives $\gamma_{\mathrm{sa}}^{\mathrm{d}}=45 \mathrm{mN} \mathrm{m}^{-1}$ and $\gamma_{\mathrm{sa}}^{\mathrm{p}}=18 \mathrm{mN} \mathrm{m}^{-1}$ for the oleophilic particles (PF-0). The value of $\gamma_{\mathrm{sa}}^{\mathrm{p}}$ is $0 \mathrm{mN} \mathrm{m}^{-1}$ for the rest of the particles, but $\gamma_{\mathrm{sa}}^{\mathrm{d}}$ decreases as the degree of (a)

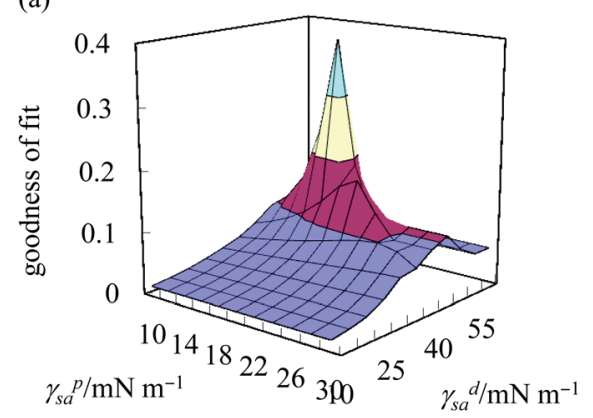

(b)

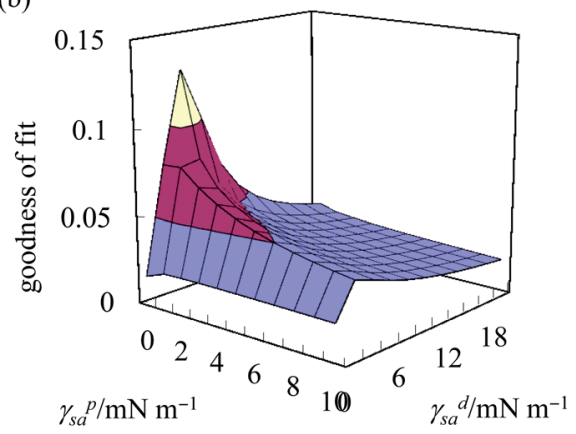

(c)

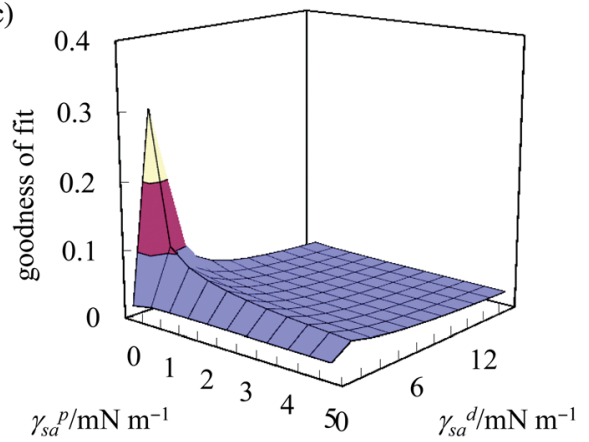

Fig. 2 Surface energy chart for (a) PF-0, (b) PF-5 and (c) PF-12 sericite particles as a function of possible values of $\gamma_{\mathrm{sa}}^{\mathrm{d}}$ and $\gamma_{\mathrm{sa}}^{\mathrm{p}}$. The ordinate represents the 'goodness of fit' which is the inverse of the sum of the squares of variances.

fluorination increases. Generally, there is an inverse correlation between the degree of fluorination and the surface energy of the

\begin{tabular}{|c|c|c|c|c|c|c|c|c|c|}
\hline \multirow[b]{2}{*}{ Liquid } & \multirow[b]{2}{*}{$\gamma_{\mathrm{la}} / \mathrm{mN} \mathrm{m}^{-1}$} & \multirow[b]{2}{*}{$\gamma_{\mathrm{la}}^{\mathrm{d}} / \mathrm{mN} \mathrm{m}^{-1}$} & \multirow[b]{2}{*}{$\gamma_{\mathrm{P}} / \mathrm{mN} \mathrm{m}^{-1}$} & \multicolumn{6}{|l|}{$\theta / \pm 2^{\circ}$} \\
\hline & & & & $\mathrm{PF}-0$ & PF-5 & PF-8 & PF-10 & PF-12 & PTFE \\
\hline Glycerol & 64.0 & 34.0 & 30.0 & 18.2 & 128.1 & 145.3 & 131.4 & 146.2 & 101.6 \\
\hline Formamide & 58.0 & 39.0 & 19.0 & 0.0 & 134.9 & 129.5 & 145.3 & 138.8 & 85.1 \\
\hline Ethylene glycol & 48.0 & 29.0 & 19.0 & 0.0 & 119.3 & 134.8 & 136.2 & 137.5 & 75.8 \\
\hline$n$-Hexadecane & 27.8 & 27.8 & 0.0 & 5.0 & 89.5 & 97.8 & 104.8 & 117.6 & 35.1 \\
\hline
\end{tabular}
particles, as expected. The surface energy of a PTFE substrate

Table 2 Surface tension and corresponding dispersion and polar components of tension of probe liquids (at $25^{\circ} \mathrm{C}$ ) as well as advancing $\theta$ of the liquid measured on compressed disks of particles and a PTFE substrate in air. The values of $\gamma_{\text {la }}$ and $\gamma_{\text {la }}^{d}$ were taken from ref. 42 
Table 3 Surface energies of sericite particles and PTFE substrate, $\gamma_{\text {sa }}$ along with their polar and dispersion components; all values are $\pm 0.3 \mathrm{mN} \mathrm{m}^{-1}$

\begin{tabular}{lccc}
\hline Particle & $\gamma_{\mathrm{sa}} / \mathrm{mN} \mathrm{m}^{-1}$ & $\gamma_{\mathrm{sa}}^{\mathrm{p}} / \mathrm{mN} \mathrm{m}^{-1}$ & $\gamma_{\mathrm{sa}}^{\mathrm{d}} / \mathrm{mN} \mathrm{m}^{-1}$ \\
\hline PF-0 & 63.0 & 18.0 & 45.0 \\
PF-5 & 4.0 & 0.0 & 4.0 \\
PF-8 & 3.0 & 0.0 & 3.0 \\
PF-10 & 2.0 & 0.0 & 2.0 \\
PF-12 & 1.5 & 0.0 & 1.5 \\
PTFE & 19.5 & 0.0 & 19.5 \\
\hline
\end{tabular}

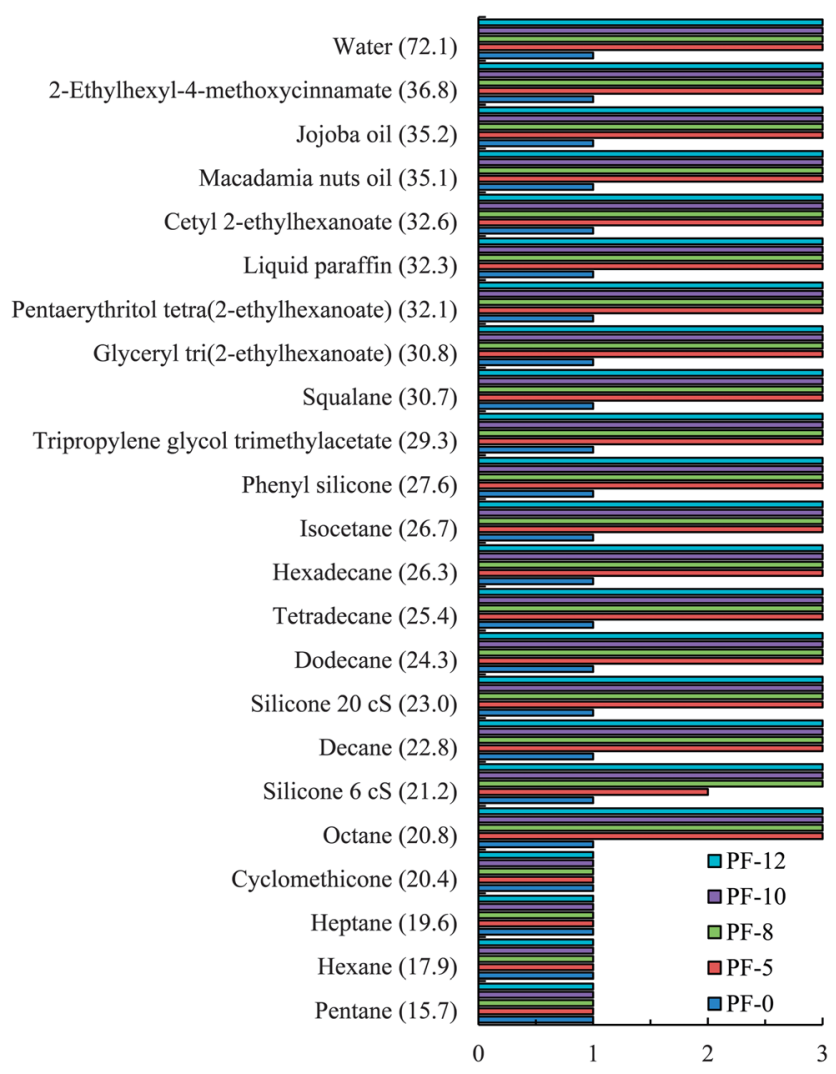

Fig. 3 Behaviour of PF-sericite particles $(50 \mathrm{mg})$ on the surface of the various liquids $\left(3 \mathrm{~cm}^{3}\right)$ at rest. Abscissa: 1-particles were wetted by the liquid, 2-particles were partially wetted by the liquid, 3-particles were not wetted by the liquid. Ordinate: number in brackets is liquid surface tension $\left( \pm 0.1 \mathrm{mN} \mathrm{m}^{-1}\right)$ at $25^{\circ} \mathrm{C}$.

(19.5 $\mathrm{mN} \mathrm{m}^{-1}$ ), measured for comparison, is consistent with literature values $\left(18.5 \mathrm{mN} \mathrm{m}^{-1}\right) .{ }^{43}$ The advancing contact angle for water on it is $119^{\circ}$, in good agreement with literature values of $108-122^{\circ} .^{\mathbf{4 4 , 4 5}}$

\section{Behaviour of particles on oil surfaces}

Fig. 3 summarises the results of the particle immersion experiment. The most oleophilic particles of PF- 0 were wetted by all the oils and water and entered them within $30 \mathrm{~s}$ at rest. On agitation, a cloudy dispersion forms in the liquids. The following behaviour was observed for the other fluorinated particles. For the relatively low tension oils $\left(\gamma_{\text {la }}\right.$ below $22 \mathrm{mN}$ $\mathrm{m}^{-1}$ ), the particles were either partially or completely wetted at rest or were not wetted at rest but entered the oil after agitation to give a cloudy dispersion. Oils of relatively high surface tension ( $\gamma_{\text {la }}$ above $22 \mathrm{mN} \mathrm{m}^{-1}$ ) did not wet the particles at rest. On agitation (apart from $20 \mathrm{cS}$ PDMS and PF-5 mixture which gave a cloudy dispersion), all the oils possessing tensions between 22 and $32 \mathrm{mN} \mathrm{m}^{-1}$ produced a foam or a foam with a climbing film. Oils with tensions between 32 and $37 \mathrm{mN} \mathrm{m}^{-1}$ gave a foam and climbing film on agitation except cetyl 2-ethylhexanoate, macadamia nuts oil and jojoba oil that gave only a foam with the least fluorinated particles and 2-ethyhexyl-4methoxycinnamate that gave only a climbing film with the most fluorinated ones. Water, possessing the highest surface tension, gave only a climbing film with the particles. Climbing films have been observed previously in water systems containing very hydrophobic solid particles and have been linked to the coalescence of unstable particle-coated bubbles with the planar air-water surface. ${ }^{46}$ As air bubbles coalesce with the surface, the interfacial area decreases thus causing an increase in the surface concentration of the adsorbed particles. This in turn leads to an increase in the surface pressure of the planar interface causing the film to climb. Photos of some of the materials formed by the particles with the various oils are shown in Fig. 4 and Fig. S3. $\uparrow$ The transition from oil dispersions to oil foams and ultimately non-wetting states as the surface tension of the liquid increases is in line with earlier predictions and findings. ${ }^{12}$

\section{Oil liquid marbles and dry oils stabilised by particles}

As mentioned earlier, oil liquid marbles can be conceived as the smallest unit of dry oil powders, although the size of a marble is significantly larger and it can be seen by eye. Marble formation was possible with most oil and particle combinations that produced oil foams described above (see Table 4). As the degree of particle fluorination increases, it is possible to encapsulate oils of lower tension and the robustness of the marbles also increased. It is generally accepted that relatively small $(\leq 10 \mu \mathrm{L})$ liquid marbles, where the effect of surface tension dominates that of gravity, are quasi-spherical, whilst relatively large $(\geq 50$ $\mu \mathrm{L}$ ) ones, where the effect of gravity dominates that of surface tension, are puddle-shaped. ${ }^{\mathbf{1 7}, \mathbf{4 7}}$ Here, however, the oil marbles $(10 \mu \mathrm{L})$ assume a sausage-like shape if the oil droplet is rolled on the particle bed (to and fro) in only one direction. Otherwise, they are quasi-spherical. The origin of the shape of these

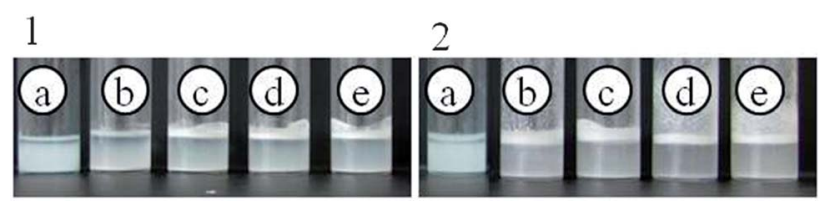

Fig. 4 Photos of vessels containing PF-(a) 0, (b) 5, (c) 8, (d) 10 and (e) 12 sericite particles $(50 \mathrm{mg})$ and liquids $\left(3 \mathrm{~cm}^{3}\right)$ after agitation for $30 \mathrm{~s}$ : (1) 20 cS PDMS-particle dispersion or oil foam and (2) squalaneparticle dispersion, oil foam or oil foam + climbing film. 
Table 4 Advancing (first entry) and receding (second entry) $\theta$ measured through the liquid of a drop of liquid in air on compressed disks of fluorinated sericite particles at room temperature. The advancing $\theta$ on PF- 0 particle disks can be approximated to $0^{\circ}$ as all liquids completely wet the disk. The materials obtained after agitation of the liquid-particle mixture are also given: $\bigcirc$-dispersion, $\boldsymbol{\Delta}$-foam, $\mathbf{\square}$-foam + climbing film, $\dagger$-climbing film. For liquid marbles: $\times$-no marble, $\boldsymbol{\checkmark}$-marble. The formation of dry oil powder stable to leakage is possible for all particle types with all oils from isocetane to 2-ethylhexyl-4-methoxycinnamate

\begin{tabular}{|c|c|c|c|c|}
\hline \multirow[b]{2}{*}{ Liquid } & \multicolumn{4}{|l|}{$\theta / \pm 2^{\circ}$} \\
\hline & PF-5 & PF-8 & PF-10 & PF-12 \\
\hline Hexane & $0,0: \bigcirc, \times$ & $0,0: \bigcirc, \times$ & $0,0: \bigcirc, \times$ & $0,0: \bigcirc, \times$ \\
\hline Heptane & $43,21: \bigcirc, \times$ & 56, 25: $\bigcirc, \times$ & 50, 29: $\bigcirc, \times$ & $46,22: \bigcirc, \times$ \\
\hline Cyclomethicone & $30,12: \bigcirc, \checkmark$ & $37,20: \bigcirc, \checkmark$ & $47,27: \bigcirc, \checkmark$ & $39,24: \bigcirc, \checkmark$ \\
\hline 20 cS PDMS & $65,42: \bigcirc, \checkmark$ & $71,35: \bigcirc, \checkmark$ & 73, 43: $\boldsymbol{\Delta}, \checkmark$ & $73,32: \bigcirc, \checkmark$ \\
\hline Decane & $66,36: \Delta, \mathcal{J}$ & $88,62: \Delta, \checkmark$ & $80,47: \boldsymbol{\Lambda}, \checkmark$ & 84, 55: $\boldsymbol{\Delta}, \checkmark$ \\
\hline Dodecane & 77, 63: $\Delta, \checkmark$ & $92,64: \Delta, \checkmark$ & 99, 65: $\Delta, \checkmark$ & 95, 59: $\boldsymbol{\Delta}, \checkmark$ \\
\hline Tetradecane & $82,47: \boldsymbol{\Lambda}, \boldsymbol{V}$ & 101, 69: $\boldsymbol{\Delta}, \checkmark$ & 106, 60: $\boldsymbol{\Delta}, \mathfrak{V}$ & 106, 73: $\boldsymbol{\Delta}, \mathcal{J}$ \\
\hline Isocetane & 63, 39: $\boldsymbol{\Delta}, \mathfrak{\checkmark}$ & $68,44: \Delta, \checkmark$ & $79,52: \Delta, \checkmark$ & $56,34: \Delta, \checkmark$ \\
\hline Hexadecane & $90,65: \Delta, \mathcal{J}$ & 98, 69: $\boldsymbol{\Delta}, \mathcal{J}$ & $105,73: \mathbf{\Delta}, \checkmark$ & 118, 93: $\boldsymbol{\Delta}, \mathcal{J}$ \\
\hline Pentaerythritol tetra(2-ethylhexanoate) & $110,59: \Delta, \checkmark$ & $101,57: \Delta, \checkmark$ & $97,55: \mathbf{\square}, \checkmark$ & 118, 64: $\mathbf{\square}, \checkmark$ \\
\hline Liquid paraffin & $109,83: \boldsymbol{\Delta}, \checkmark$ & $121,88: \square, \checkmark$ & $121,87: \mathbb{a}, \checkmark$ & 126, 87: $\mathbf{\square}, \mathfrak{J}$ \\
\hline Cetyl 2-ethylhexanoate & 112, 75: $\boldsymbol{\Delta}, \checkmark$ & $111,73: \mathbf{\square}, \checkmark$ & $94,70: \square, \mathfrak{V}$ & 96, 71: $\mathbf{\square}, \checkmark$ \\
\hline Macadamia nuts oil & $112,76: \Delta, \checkmark$ & 101, 80: $\mathbf{\square}, \checkmark$ & $115,83: \mathbf{a}, \checkmark$ & 128, 94: $\mathbf{\square}, \checkmark$ \\
\hline Jojoba oil & 113, 78: $\boldsymbol{\Delta}, \boldsymbol{J}$ & $121,88: \mathbf{\square}, \checkmark$ & $114,82: \square, \checkmark$ & $123,94: \boldsymbol{\square}, \checkmark$ \\
\hline 2-Ethylhexyl-4-methoxycinnamate & $91,64: \mathbf{\square}, \mathfrak{\checkmark}$ & $117,77: \mathbf{a}, \checkmark$ & $113,81: \mathbf{\square}, \mathfrak{J}$ & $118,77: \dagger, \checkmark$ \\
\hline Water & 140, 111: $\dagger, \checkmark$ & 148, 119: $\dagger, \checkmark$ & $138,123: \dagger, \checkmark$ & $148,127: \dagger, \checkmark$ \\
\hline
\end{tabular}

relatively small liquid marbles is not clear at the moment, but might be due to the shape and/or density of the particles.

Following successful preparation of liquid marbles with these oils and fluorinated particles, attempts were made at preparing dry oil powders from them too. This was done in five different ways as stated earlier, conscious of the COPR, with the best being the sequential approach whose results are discussed here. Dry oil powder formation was possible with the majority of the oil and particle combinations that formed oil marbles. Fig. 5(a) shows that the COPR increases with an increase in the degree of fluorination on particle surfaces. The effect of the degree of fluorination and hence particle surface energy on the COPR is shown in Fig. 5(b) for isocetane, glyceryl tri(2-ethylhexanoate) and 2-ethylhexyl-4-methoxycinnamate. An inverse correlation exists between particle surface energy and the COPR. The amount of oil encapsulated within powders ranges from 44 (dry isocetane powder stabilised by PF-5 particles) to 81 wt\% (2-ethylhexyl-4-methoxycinnamate powder stabilised by PF-12 particles), the latter exceeding that reported earlier ${ }^{22}$ by a factor of five. Similar to liquid marble formation, the most oleophilic and relatively high surface energy particles did not adsorb at the air-liquid interfaces and thus did not enable dry oil formation. Dry oil formation for the rest of the particles and with oils possessing $\gamma_{\mathrm{la}}$ below $25 \mathrm{mN} \mathrm{m}^{-1}$ (i.e. cyclomethicone, 6 and $20 \mathrm{cS}$ PDMS) was also not possible even though marbles could be prepared. Dry oil powders were successfully prepared from the rest of the oils and particle types via sequential addition of the required amount of oil to the particles, followed by low shear up to the COPR. Formation of dry water was not possible by this route because of the large difference between its surface tension and the surface energy of the particles. In addition, the high surface tension of water did not allow disruption of a big water drop into smaller droplets by gentle shaking unlike the case with the relatively low tension oils. Photos of some dry oil powders and their corresponding optical micrographs (alongside photos of some oil marbles) are shown in Fig. 6 and 7, respectively. It can be seen that the oil droplets $(>100 \mu \mathrm{m})$ within the powders are non-spherical in shape. Such deviation from spherical shape has been reported previously for particle-coated fluid dispersed phases and is due to the jamming of particles at the interface preventing their relaxation to a spherical geometry. ${ }^{48} \mathrm{~A}$ cryo-SEM image from an oil powder is included in Fig. 7 where a fractured oil drop coated with particles containing frozen oil within is clearly visible. Other images of the same oil powder are given in Fig. S4. $\dagger$

The absence of significant oil staining upon placing the dry oil powders on a filter paper and watch glass suggests that the oil droplets in the powder are stable against oil leakage. Apart from the $n$-alkanes that released some of the encapsulated oil droplets after one week, the dry oil powders are stable to oil leakage and hence to phase separation for at least 8 months, but liquefy and cream releasing the encapsulated oil when sheared on the skin or a surface (Fig. S5 †), except in cases where the oil content (relative to the total mass of powder) is less than $60 \mathrm{wt} \%$ 

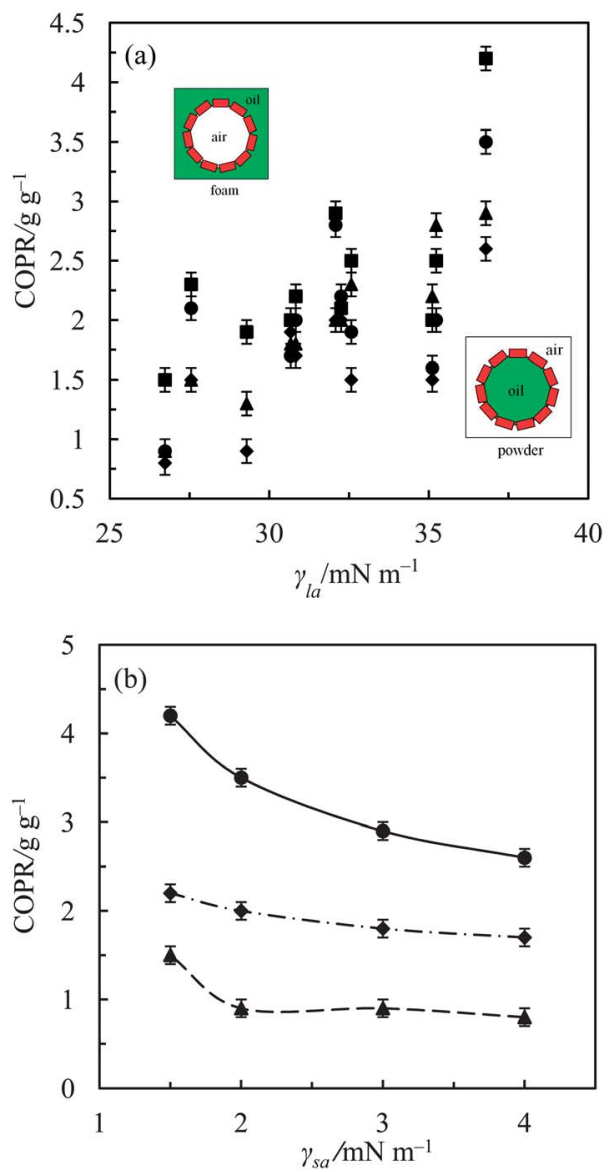

Fig. 5 The critical oil : particle ratio versus (a) surface tension of the

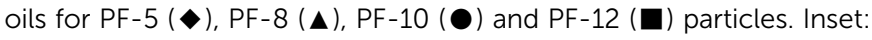
schematic of air-in-oil foam above COPR and dry oil powder at or below COPR and (b) surface energy of the particles for isocetane ( $\boldsymbol{\Lambda})$, glyceryl tri(2-ethylhexanoate) ( ) and 2-ethylhexyl-4-methoxycinnamate (1). For simplicity, the oil droplets and air bubbles are spherical. The error bars represent the minimum amount of oil required for phase inversion per gram of particles.

which form a white paste. The latter dry oil powders invert to oil foams upon vigorous shaking as verified with squalane, liquid paraffin and jojoba oil stabilised by PF-8 particles. This suggests that the dry oil powders are metastable with the stable state being an oil foam.

\section{Catastrophic phase inversion of dry oil powders to oil foams at high oil : particle ratio}

Above the COPR, catastrophic phase inversion from a dry oil powder to an ultra-stable oil foam was observed for all the oils and the stable air bubbles coated with particles are also nonspherical but smaller than the oil droplets in the dry oil powders. Particle stabilised non-aqueous foams of excellent stability, in which the gas bubbles deviated from spherical geometry, were reported previously. ${ }^{6,7,22}$ Phase inversion was confirmed by verification of the continuous phase of the materials through the dispersion test. The dry oil powders did not disperse in the neat oils whereas the foams readily did (Fig. S5†). This phase inversion is similar to that in emulsions

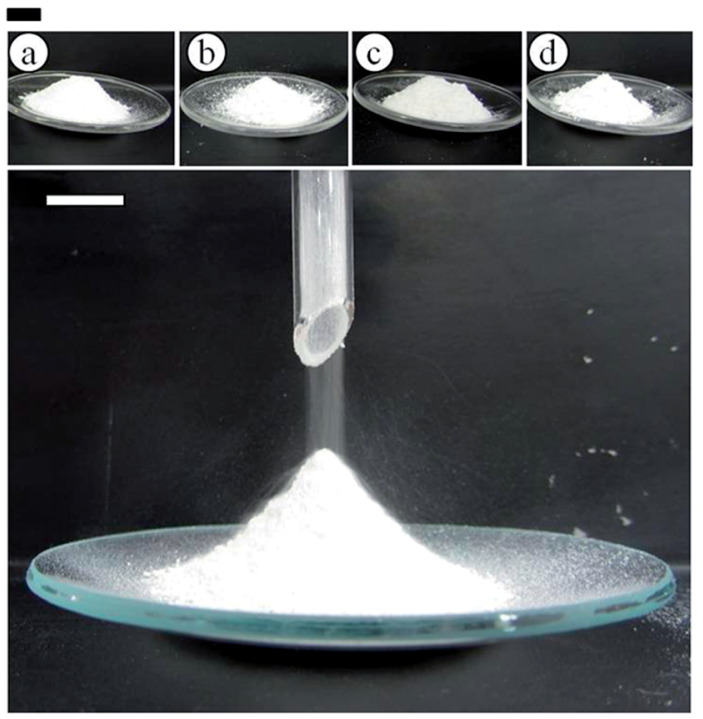

Fig. 6 (upper) Photos of watch glasses containing dry oil powders 1 month after formation of (a) squalane, (b) liquid paraffin, (c) cetyl 2ethylhexanoate, and (d) macadamia nuts oil stabilised by PF-12 sericite particles. (lower) Photo of corresponding dry liquid paraffin powder flowing through a glass funnel onto a Pyrex watch glass. Scale bar $=10 \mathrm{~mm}$.

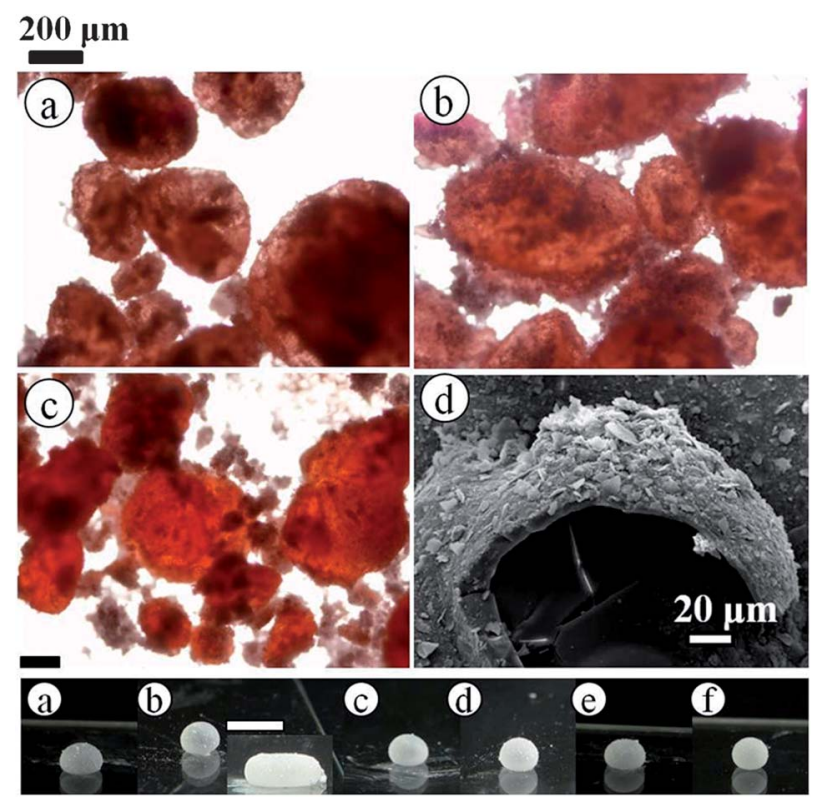

Fig. 7 (upper) Optical micrographs soon after formation of dry (a) squalane powder stabilised by PF-5, (b) liquid paraffin powder stabilised by PF-8, (c) cetyl 2-ethylhexanoate powder stabilised by PF-10 and (d) cryo-SEM image of 2-ethylhexyl-4-methoxycinnamate oil powder stabilised by PF-12 particles. The oils $\left(10 \mathrm{~cm}^{3}\right)$ were coloured with Sudan red dye (ca. $5 \mathrm{mg}$ ) to aid visualisation. (lower) Photos of liquid marbles $(10 \mu \mathrm{L})$ resting on a hydrophilic glass slide in air stabilised by PF-12 sericite particles soon after formation. The liquid is (a) phenyl silicone, (b) squalane, (c) pentaerythritol tetra(2-ethylhexanoate), (d) jojoba oil, (e) 2-ethylhexyl-4-methoxycinnamate and (f) water. The inset in (b) is a $10 \mu \mathrm{L}$ squalane droplet rolled in only one direction to and fro. Scale bar $=3 \mathrm{~mm}$. 


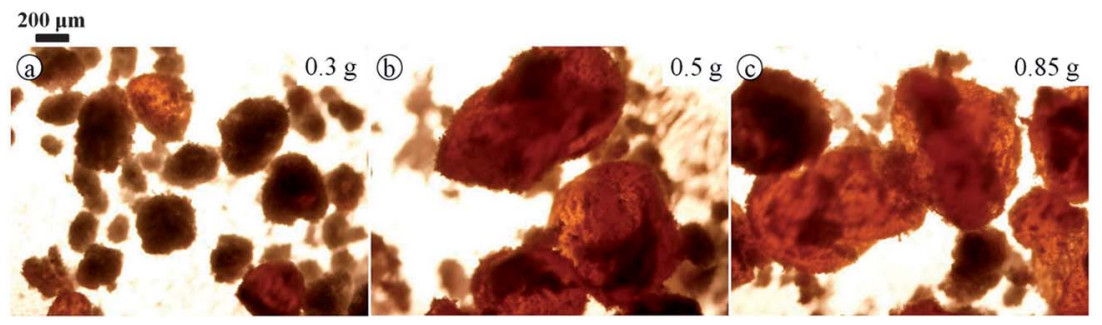

Fig. 8 Optical micrographs of dry liquid paraffin powder stabilised by $0.5 \mathrm{~g}$ of PF- 8 sericite particles containing various amounts of liquid paraffin (given).

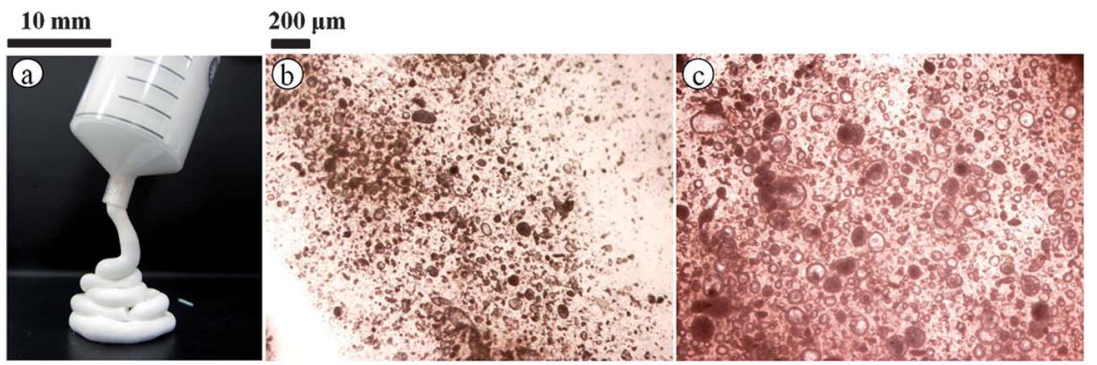

Fig. 9 (a) Photo of liquid paraffin foam stabilised by PF-12 particles, obtained from phase inversion of its corresponding powder, forced out of a plastic syringe onto a black aluminium substrate, (b) corresponding optical micrograph of liquid paraffin foam and (c) squalane foam stabilised by PF-5 particles obtained from phase inversion of its powder. Both foams were viewed soon after formation.

(i.e. $\mathrm{o} / \mathrm{w}$ to $\mathrm{w} / \mathrm{o}$ and vice versa $)^{49}$ and is driven by the high oil : particle ratio. Increasing the oil content at fixed mass of particles can potentially increase the size of the oil droplets or their number in the dry oil powder, but reduce the amount of non-adsorbed particles in the system. Evidence from Fig. 8, for PF-8 particles containing different amounts of liquid paraffin, suggests that the former is favoured over the latter. Above the COPR, there are little or no particles to sufficiently coat the oil droplets following oil addition. In other words, the total amount of oil surfaces the particles can coat and stabilise in the form of dry oil powder is greater than that of the air surfaces trapped in the vessel. This makes the oil-in-air powder metastable and hence it inverts to the stable air-in-oil foam (Fig. 9) upon gentle shaking. Such a catastrophic phase inversion has also been reported in aqueous systems in the context of dry water. ${ }^{21}$ Most of the oil foams did not show any sign of drainage or coalescence indefinitely, but some of them underwent limited drainage within the first week after formation to yield very stable foams subsequently. These were those of squalane or 2-ethylhexyl-4-methoxycinnamate stabilised by PF-8, cetyl 2-ethylhexanoate stabilised by PF-10 and either glyceryl tri(2ethylhexanoate), pentaerythritol tetra(2-ethylhexanoate) or jojoba oil stabilised PF-12 particles.

\section{Relationship between air-liquid-solid contact angle and the type of material formed}

Since the kind of material a mixture of air, liquid and solid particles produces depends on the contact angle which the particles make with the liquid, it is important to have an idea of this angle here. For spherical particles it is generally accepted that if a liquid completely wets the particles $\left(\theta=0^{\circ}\right)$ it gives a particle dispersion and for $\theta=180^{\circ}$ no adsorption occurs. For intermediate values of $\theta$, particles are more wetted by the liquid $\left(\theta<90^{\circ}\right)$ or air $\left(\theta>90^{\circ}\right)$ phase and foams or liquid marbles/dry liquid powders are stabilised, respectively, at least in the case of water. ${ }^{\mathbf{4} 21}$ However, the contact angles reported here are not on the particles themselves but on disks composed of the particles with the danger being that certain surface groups are buried during particle compression. In addition, the particles are platelike and the possibility exists that the fluoro-coating may be different on the edges compared with the faces. The configuration of such asymmetric particles at the fluid interface within materials like oil foams and oil powders is unknown at present although Garrett discusses the likely configurations, albeit at an air-water surface, which depends on the particle geometry. ${ }^{50}$ As a result, unravelling a clear correlation between contact angle and material type is obviously a challenge. Table 4 shows both the advancing and receding values of $\theta$ alongside the type of material that was obtained from the various oil and particle combinations in the case of vigorous mixing and gentle agitation. The liquids are arranged in order of increasing $\gamma_{\text {la }}$. For the oleophilic sericite particles (PF-0), all the liquids wet the particle disks as expected $\left(\theta<5^{\circ}\right)$. For the other particles, the hysteresis is relatively high (above $15^{\circ}$ ). Since hysteresis in contact angle is quite low for rough surfaces, ${ }^{51}$ what we observe may be due to the smooth nature of the surfaces of these disks. ${ }^{15}$ Particle dispersions in oil were obtained in liquids of relatively low $\gamma_{\text {la }}$. In cases where $\gamma_{\text {la }}$ was moderate (between 27 and $37 \mathrm{mN} \mathrm{m}^{-1}$ ) and $\theta$ was between 70 and $120^{\circ}$, an oil foam or a foam + climbing film was observed. For water (highest $\gamma_{\mathrm{la}}$ ) where $\theta \geq$ $140^{\circ}$, only climbing films were observed. In addition, liquid oil 
marbles form not just for high contact angle systems, e.g. jojoba oil with PF-12, but also when the angle is as low as $30^{\circ}$, e.g. cyclomethicone with PF-5. This is very different to the case of liquid water marbles where particles required to date are all very hydrophobic. We admit however that the robustness of the marbles to transport decreases as the apparent contact angle decreases. Dry oil powder formation was possible with most of the oil-particle combinations which stabilised liquid oil marbles as expected. It was not possible for oils of lower $\gamma_{\text {la }}$, for example low chain length alkanes. A number of conclusions can be extracted from Table 4. Firstly, for all the fluorinated particles, there is a transition from a dispersion to a foam to a climbing film as $\gamma_{\text {la }}$ increases. Secondly, foams and marbles can be stabilised in one and the same system depending on the mixing conditions. Thirdly, omniphobic surfaces can be created with these fluorinated particles.

The cosine of both the advancing and receding contact angles on particle disks is plotted as a function of $\gamma_{\text {la }}$ in Fig. 10. For certain smooth substrates, such plots are often linear of negative gradient. ${ }^{52}$ The inset in Fig. 10(a) shows an example of
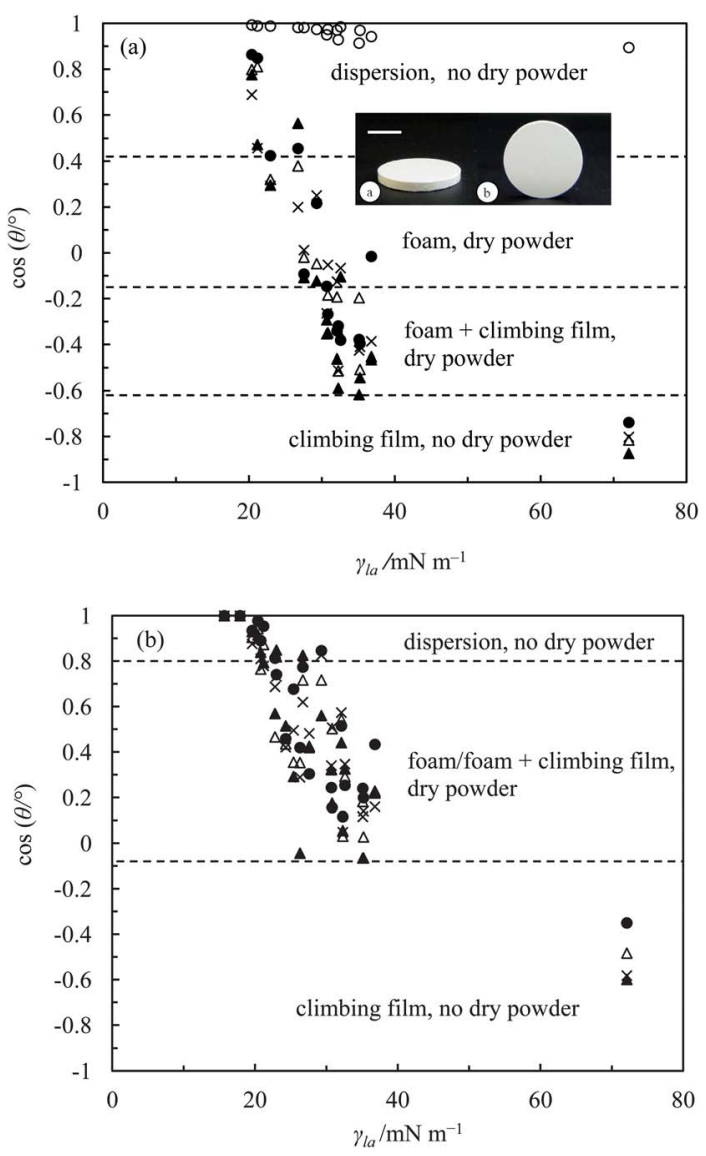

Fig. 10 Cosine of (a) advancing and (b) receding $\theta$ of a liquid droplet in air on compressed particle disks of PF-0 (O), PF-5 ( ), PF-8 $(\triangle)$, PF$10(x)$ and PF-12 $(\boldsymbol{\Lambda})$ particles as a function of $\gamma_{\text {la }}\left(\right.$ at $25^{\circ} \mathrm{C}$ ). Inset: photograph of (a) side and (b) top view of a PF-10 sericite disk made by compressing the powdered particles (scale bar $=6 \mathrm{~mm}$ ). The type of material formed on vigorous agitation and with gentle mixing is also indicated. one of the disks on which $\theta$ was measured. The value of the cosine of the advancing angle is more or less unity for all the liquids on PF-0 surfaces, but decreases with increasing $\gamma_{\mathrm{la}}$ on the fluorinated particle surfaces as does the receding angle (Fig. 10(b)). We also label on the graphs the regions where either dispersions, foams or climbing films occur upon intense agitation or whether a dry oil powder can be formed or not upon gentle mixing. Since the receding contact angle is always less than the advancing one, the boundaries between the different regions depend on which angle is taken. It is not clear which angle is operative during the mixing of particles with liquid. Indeed, in the case of oil-water systems, the emulsion type depended on which liquid contacted the particles first which was argued in terms of the difference between the advancing and receding contact angle. ${ }^{53}$ The main point about this figure is that for any particle type, a particle dispersion forms when $\cos \theta$ is approximately 1 , foams are stabilised as it decreases and eventually only climbing films are stabilised when it is close to -1 . This is consistent with previous findings with PTFE particles $^{6}$ and fluorinated silica particles. ${ }^{7}$

\section{Conclusions}

The behaviour of a series of platelet sericite particles coated to different extents with a fluorinating agent in mixtures with air and oil has been studied. The material which forms after aeration by vigorous shaking depends on both the surface tension of the oil and the surface energy of the particles which control their degree of wetting. Oil dispersions are formed in liquids of relatively low tension $\left(<22 \mathrm{mN} \mathrm{m}^{-1}\right)$. Particle-stabilised air-in-oil foams form in liquids of higher tension where the three-phase contact angle $\theta$ measured on planar disks composed of the particles lies between $\mathrm{ca} .70$ and $125^{\circ}$. For oils of tension above $27 \mathrm{mN} \mathrm{m}^{-1}$ with particles for which $\theta>70^{\circ}$, we have discovered that dry oil powders in which oil drops stabilised by particles are dispersed in air (o/a) can be prepared by gentle mixing up to a critical oil : particle ratio (COPR) and do not leak oil. These powders containing at least $60 \mathrm{wt} \%$ oil release the encapsulated oil however when sheared on a substrate. For many of the systems forming oil powders, stable oil liquid marbles can also be prepared. Above the COPR, catastrophic phase inversion occurs yielding an ultra-stable oil foam $(\mathrm{a} / \mathrm{o})$.

\section{Acknowledgements}

We are grateful to the Tertiary Education Trust Fund of Nigeria and the University of Hull for a studentship to ATT, Shiseido (Japan) for partial financial support and Mr A. Sinclair (Univ. of Hull) for the SEM images and EDX spectra.

\section{References}

1 W. Ramsden, Proc. R. Soc. London, 1903, 72, 156.

2 S. U. Pickering, J. Am. Chem. Soc., 1907, 91, 2001.

3 R. Aveyard, B. P. Binks and J. H. Clint, Adv. Colloid Interface Sci., 2003, 100-102, 503. 
4 B. P. Binks and T. S. Horozov, Angew. Chem., Int. Ed., 2005, 44, 3722 .

5 U. T. Gonzenbach, A. R. Studart, E. Tervoort and L. J. Gauckler, Langmuir, 2006, 22, 10983.

6 B. P. Binks, A. Rocher and M. Kirkland, Soft Matter, 2011, 7, 1800.

7 B. P. Binks and A. T. Tyowua, Soft Matter, 2013, 9, 834.

8 J. H. Schulman and J. Leja, Trans. Faraday Soc., 1954, 50, 598.

9 A. Stocco, E. Rio, B. P. Binks and D. Langevin, Soft Matter, 2011, 7, 1260.

10 P. Aussillous and D. Quéré, Nature, 2001, 411, 924.

11 P. McEleney, G. M. Walker, I. A. Larmour and S. E. J. Bell, Chem. Eng. J., 2009, 147, 373.

12 B. P. Binks and A. Rocher, Phys. Chem. Chem. Phys., 2010, 12, 9169.

13 Y.-C. Sheen, Y.-C. Huang, C.-S. Liao, H.-Y. Chou and F.-C. Chang, J. Polym. Sci., Part B: Polym. Phys., 2008, 46, 1984.

14 R. Campos, A. J. Guenthner, T. S. Haddad and J. M. Mabry, Langmuir, 2011, 27, 10206.

15 A. Tuteja, W. Choi, J. M. Mabry, G. H. McKinley and R. E. Cohen, Proc. Natl. Acad. Sci. U. S. A., 2008, 105, 18200.

16 N. Eshtiaghi and K. P. Hapgood, Powder Technol., 2012, 223, 65.

17 P. Aussillous and D. Quéré, Proc. R. Soc. London, Ser. A, 2006, 462, 973.

18 E. Bormashenko, Curr. Opin. Colloid Interface Sci., 2011, 16, 266.

19 E. Bormashenko and A. Musin, Appl. Surf. Sci., 2009, 255, 6429.

20 J. Tian, T. Arbatan, X. Li and W. Shen, Chem. Commun., 2010, 46, 4734.

21 B. P. Binks and R. Murakami, Nat. Mater., 2006, 5, 865.

22 R. Murakami and A. Bismarck, Adv. Funct. Mater., 2010, 20, 732.

23 W. Barthlott and C. Neinhuis, Planta, 1997, 202, 1.

24 N. Pike, D. Richard, R. Foster and L. Mahadevan, Proc. R. Soc. London, Ser. B, 2002, 269, 1211.

25 P. A. Kralchevsky and K. Nagayama, Adv. Colloid Interface Sci., 2000, 85, 145.

26 B. P. Binks, A. J. Johnson and J. A. Rodrigues, Soft Matter, 2010, 6, 126.

27 B. P. Binks, B. Duncumb and R. Murakami, Langmuir, 2007, 23, 9143.
28 L. Forny, I. Pezron, K. Saleh, P. Guigon and L. Komunjer, Powder Technol., 2007, 171, 15.

29 L. Forny, K. Saleh, R. Denoyel and I. Pezron, Langmuir, 2010, 26, 2333.

30 B. O. Carter, D. J. Adams and A. I. Cooper, Green Chem., 2010, 12, 783.

31 B. O. Carter, W. Wang, D. J. Adams and A. I. Cooper, Langmuir, 2010, 26, 3186.

32 R. Mezzenga and S. Ulrich, Langmuir, 2010, 26, 16658.

33 H. Adelmann, B. P. Binks and R. Mezzenga, Langmuir, 2012, 28, 1694.

34 R. Murakami, H. Moriyama, M. Yamamoto, B. P. Binks and A. Rocher, Adv. Mater., 2012, 24, 767.

35 B. O. Carter, J. V. M. Weaver, W. Wang, D. G. Spiller, D. J. Adams and A. I. Cooper, Chem. Commun., 2011, 47, 8253.

36 Y.-S. Perng, E. I.-C. Wang, C.-C. Lu and L.-S. Kuo, Tappi J., 2008, 3, 21.

37 D. D. Eberl, J. Srodon, M. Lee, P. H. Nadeau and H. R. Northrop, Am. Mineral., 1987, 72, 914.

38 F. M. Fowkes, J. Phys. Chem., 1963, 67, 2538.

39 D. K. Owens and R. C. Wendt, J. Appl. Polym. Sci., 1969, 13, 1741.

40 C. J. Van Oss, Interfacial Forces in Aqueous Media, Marcel Dekker, New York, 1994.

41 T. Young, Philos. Trans. R. Soc. London, 1805, 95, 65.

42 J. H. Clint and A. C. Wicks, Int. J. Adhes. Adhes., 2001, 21, 267.

43 C. J. Van Oss and R. F. Giese, Clays Clay Miner., 1995, 43, 474.

44 J. Zhang, J. Li and Y. Han, Macromol. Rapid Commun., 2004, 25, 1105.

45 C. W. Extrand and Y. Kumagai, J. Colloid Interface Sci., 1995, 170, 515.

46 B. P. Binks, J. H. Clint, P. D. I. Fletcher, T. J. G. Lees and P. Taylor, Chem. Commun., 2006, 3531.

47 E. Bormashenko, R. Progreb, G. Whyman and A. Musin, Colloids Surf., A, 2009, 351, 78.

48 A. B. Subramaniam, M. Abkarian, L. Mahadevan and H. A. Stone, Langmuir, 2006, 22, 10204.

49 B. P. Binks, L. Isa and A. T. Tyowua, Langmuir, 2013, 29, 4923. 50 P. R. Garrett, in Defoaming: Theory and Industrial Applications, ed. P.R. Garrett, Surfactant Science Series, Marcel Dekker, New York, 1993, vol. 45, p. 1.

51 D. Quéré, Annu. Rev. Mater. Res., 2008, 38, 71.

52 H. W. Fox and W. A. Zisman, J. Colloid Sci., 1952, 7, 428.

53 B. P. Binks and J. A. Rodrigues, Langmuir, 2003, 19, 4905. 